\title{
Transesterification of Low FFA Waste Vegetable Oil using Homogeneous Base Catalyst for Biodiesel Production: Optimization, Kinetics and Product Stability
}

\author{
E.G. Al-Sakkari ${ }^{1},{ }^{*}$, S.T. El-Sheltawy ${ }^{1}$, A. Soliman ${ }^{1}$, I. Ismail ${ }^{2}$ \\ ${ }^{1}$ Chemical Engineering Department, Faculty of Engineering, Cairo University, Egypt. \\ ${ }^{2}$ Renewable Energy Engineering Program, Zewail City of Science and Technology, Egypt.
}

\section{ART ICLE DETAILS}

Article history:

Received 04 October 2018

Accepted 23 October 2018

Available online 28 October 2018

\section{Keywords:}

Waste Vegetable Oil

Biodiesel

Optimization

Kinetic Modeling

Stability

\begin{abstract}
A B S T R A C T
The most common method of biodiesel production is base catalyzed transesterification where alkaline materials, such as potassium hydroxide, are used as a catalyst. This paper presents a study of factors affecting biodiesel production from low free fatty acids (FFA) content waste vegetable oil through base catalyzed transesterification as well as the optimum reaction conditions. The optimum conditions were found to be a time of $60 \mathrm{~min}$, catalyst loading of $1 \%$ of oil mass, mixing speed of $400 \mathrm{rpm}$ and temperature of $65{ }^{\circ} \mathrm{C}$. It also introduces a kinetic study of this reaction to determine the best model to fit the experimental data. First order model was found to be the best one to fit the early reaction stages while the second order model was the best to describe reaction kinetics in later stages. The stability of produced biodiesel was studied through determination of acid value and viscosity of stored biodiesel along three months.
\end{abstract}

\section{Introduction}

Biodiesel is an alternative liquid biofuel for petro-diesel [1] consisting of mixture of methyl or ethyl esters [2]. It is produced through an organic reaction called transesterification where low molecular weight alcohol e.g. methanol or ethanol- reacts with lipid or fat (triglyceride) to produce biodiesel -fatty acid methyl ester (FAME) or fatty acid ethyl ester (FAEE) and glycerol as a valuable byproduct [3]. Transesterification can occur catalytically or without catalyst [4, 5]. Catalysts currently used in transesterification process are homogeneous base or acid catalysts [6], heterogeneous catalysts [7], acid [8] or base [9] and enzymes [10,11]. Hydrodynamic cavitation technology is a new method, under research, for biodiesel production in presence of catalyst has the advantage of achieving complete conversion in a short reaction time [12, 13]. Non-catalytic transesterification can be done in presence of co-solvent such as tetrahydrofuran (THF) [14] or at supercritical conditions (e.g. high pressure up to $35 \mathrm{MPa}$ and high temperatures up to $250-300^{\circ} \mathrm{C}$ ) [15].

Homogeneous base-catalyzed transesterification involves reaction of oil e.g. vegetable oil [16], waste vegetable oil [17], non-edible oils [18] such as jatropha oil [19] and oil extracted from algae [20] with alcohol using base catalyst such as sodium hydroxide [21] or potassium hydroxide [22] to produce biodiesel and a valuable byproduct glycerin used in making cosmetics, pharmaceuticals and other valuable products [23]. The resulting products are then further processed (after using gravity separation). Distillation is applied for both ester layer and glycerol layer to recover unreacted methanol $[24,25]$. Washing with water is performed to clean biodiesel from impurities such as soap and catalyst traces [26]. Base catalyst present in glycerol layer is neutralized with mineral acid (e.g. phosphoric acid) to produce a valuable product that is removed and used as a fertilizer.

It is the most used method due to economic aspects since it requires low temperatures and pressures, reaches over $98 \%$ conversion [27] (but this requires low moisture and free fatty acids in the oil) and produces biodiesel directly without any intermediate products [28]. Also, it does not need special materials of construction of equipment used [29].

On the other hand it has some limitations [30] as it is sensitive to free fatty acids (FFA) content of the feedstock oil. If the FFA content is greater than 2 wt $\%$ of oil, this will lead to increase saponification that lowers catalyst efficiency and makes reaction medium more viscous. Soap formation favors gel formation which makes the separation of byproduct glycerol difficult. Another limitation is moisture content as the presence of water favors hydrolysis of the produced ester as well as soap formation [31].

The aim of this paper is to study the factors affecting biodiesel production (i.e. temperature, catalyst loading $\mathrm{wt} \%$, time and agitation speed) from low FFA content waste vegetable oil WVO and introduces an optimization of these factors to obtain the maximum oil conversion. Another aim of this paper is to study the kinetics of WVO transesterification through homogeneous base catalyzed process to obtain the best kinetic model that fits the experimental data. After producing biodiesel at the optimum conditions the product stability over storage was studied.

\section{Experimental Methods}

\subsection{Materials}

In this study a commercially waste vegetable oil mixture of (soybean and sunflower) having the properties shown in Table 1 was used.

Table 1 Some properties of used waste vegetable oil (WVO)

\begin{tabular}{ll}
\hline Property & Value \\
\hline Density kg m & -3 \\
Acid Value mg KOH/g & 902 \\
Saponification Value $\mathrm{mg} \mathrm{KOH} / \mathrm{g}$ & 2.5 \\
Viscosity $\mathrm{mm}^{2} \mathrm{~s}^{-1}$ at $20^{\circ} \mathrm{C}$ & 200 \\
Water content $\mathrm{wt} \%$ & 50 \\
Solid content wt $\%$ & $<0.01 \%$ \\
\hline
\end{tabular}

Pure sodium hydroxide $\mathrm{NaOH}$ and potassium hydroxide $\mathrm{KOH}$ as alkaline catalysts and methyl, ethyl, propyl and isobutyl alcohols of $99.5 \%$ purity as well as phenolphthalein indicator were used. These analytical grade chemicals were obtained from El-Nasr Pharmaceutical Chemicals Co. ADWIC Company. 


\subsection{Transesterification Reaction}

The transesterification was carried out in $500 \mathrm{~mL}$ reaction flasks equipped with condenser, magnetic stirrer and thermometer. The transesterification process was studied using four catalyst loadings $0.2 \%$, $1.0 \%, 1.5 \%$ and $2.0 \% \mathrm{KOH}$, wt $\%$, and the same loadings were used for $\mathrm{NaOH}$, five reaction temperatures $65,60,55,50$ and $35^{\circ} \mathrm{C}$ and one alcoholto-oil molar ratio 6:1 for each type of alcohol was used during the study at a reaction time of $7.5 \mathrm{~min}$ to $1.5 \mathrm{~h}$. The catalyst was dissolved into methanol, one hundred grams of the oil was introduced into the reaction flask. After the appropriate temperature was reached, $(\mathrm{KOH}$ or $\mathrm{NaOH})$ previously dissolved in alcohol was added and the mixture was continuously stirred at $400 \mathrm{rpm}$ (also the agitation speed was changed from zero rpm to $800 \mathrm{rpm}$ ) by means of a magnetic stirrer. After the preestablished time, the mixture was carefully transferred to a separating funnel and allowed to stand there overnight. The lower layer which contains glycerol, methanol and most of the catalysts was drained out. The upper layer, methyl esters, some methanol and traces of the catalyst, was then cleaned thoroughly by heating up to $105{ }^{\circ} \mathrm{C}$ in order to remove unreacted methanol and then filtered to remove any suspended solids.

Percentage conversion was estimated by weighing the produced glycerol and dividing this value by the theoretical glycerol mass obtained after complete conversion [32,33] as illustrated in Eq.(1). At complete conversion of one mole of oil one mole of glycerol is produced. On mass basis, each $100 \mathrm{~g}$ of oil produce about $10 \mathrm{~g}$ of glycerol.

conversion $(\%)=\frac{\text { mass of produced glycerol }}{\text { mass of produced glycerol at complete conversion }} * 100 \%$

The oil conversion and the produced biodiesel purity as well as its fatty acids methyl ester composition were characterized using Agilent HP 6890 GC system equipped with flame ionization detector FID. The column used was hp 5 column type of 30 meter length and $0.5 \mathrm{~mm}$ internal diameter. It was found that the concentration of partial glycerides was too small and negligible. In addition, the results obtained from GC analysis match those obtained from weighing the produced glycerol and using Eq.(1).

\subsection{Reaction Kinetics}

Kinetics of base catalyzed WVO transesterification was studied at four different temperatures. Six power law models were suggested to describe the reaction kinetics. The first three models were based on the assumption that the reaction is not reversible due to introducing methanol in high excess -i.e. $100 \%$ excess- while the other models took into consideration the reversibility of the reaction. The mechanism of homogeneous base catalyzed transesterification is illustrated below.

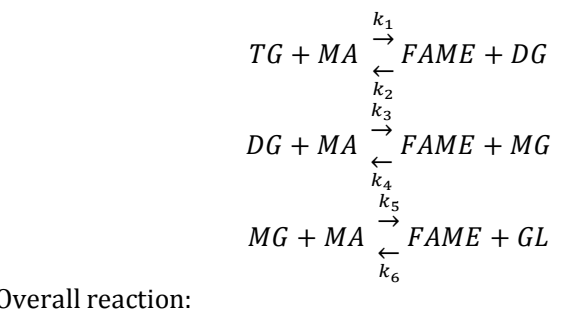

$$
T G+3 M A \stackrel{k_{t}}{\stackrel{\leftarrow}{\rightarrow}} 3 F A M E+G L
$$

As observed from previous experiments and studies, the concentrations of partial glycerides -i.e. monoglycerides MG and diglycerides DG- were almost constant and negligible compared to other substances -i.e. methanol MA, oil TG, methyl esters FAME and glycerol GL- inside reaction medium along reaction time which indicates that these intermediate steps are fast. According to the previous observation the overall reaction was considered the only step to represent the transesterification reaction and to be used in kinetics calculations [34, 35]. After calculations, the applicability and reliability of these assumptions were examined using different statistical tests.

The reaction rate ( $\mathrm{r}$ ) may be mathematically presented as in Eq.(2):

$$
r=k_{t} *[T G] *[M A]^{3}-k_{-t} *[F A M E]^{3} *[G L]
$$

Calculation of determination coefficient $\left(\mathrm{R}^{2}\right)$ and using minimization of squared error summation method were used to determine which model is the best one to fit the experimental data.

\subsubsection{Irreversible Models}

In this part of the kinetic study, methanol concentration was considered to be constant due to its use in high excess so the general rate (r) equation will be:

$$
r=K *[T G]-k_{-t} *[F A M E]^{3} *[G L]
$$

where, $\quad r=-\frac{d[T G]}{d t}$

Another assumption was suggested in this section that the reaction is not reversible due to excess methanol introduced to reaction medium which shifts the reaction to the forward direction.

$$
\begin{array}{lll}
\text { 1- } & r=K *[T G] & \text { First order in triglyceride (TG) concentration } \\
\text { 2- } & r=K *[T G]^{2} & \text { Second order in triglyceride concentration }
\end{array}
$$

On assuming that the concentration of methanol changes with time, Eq.(5) can be obtained:

$$
r=k_{t} *[T G] *[M A]^{3}
$$

In the case of irreversible first order model natural logarithm of triglyceride concentration was plotted versus reaction time to obtain the rate constant while in second order model case the plot was between the inverse of triglyceride concentration and reaction time.

Another method was employed to obtain the constant of kinetic model presented in equation 4 where average rate was plotted versus $[T G] *$ $[M A]^{3}$.

\subsubsection{Reversible Models}

In this part, the first assumption in the previous part is the only valid one while the other assumption about the irreversibility is not. So the forms of suggested rate equation will be:

1- $r=K *[T G]-k_{-t} *[F A M E]^{3} *[G L] \quad$ First order in triglyceride concentration

2- $r=K *[T G]^{2}-k_{-t} *[F A M E]^{3} *[G L]$ Second order in triglyceride concentration

On assuming that the concentration of methanol changes with time, Eq.(6) can be obtained:

$r=k_{t} *[T G] *[M A]^{3}-k_{-t} *[F A M E]^{3} *[G L]$

Least squares method with the aid of Polymath 6.0 software for curve fitting and data plotting [36] were used to obtain the parameters of each suggested model in this part.

\subsubsection{Activation Energies and Pre-exponential Factors}

To calculate the activation energies and pre exponential factors of each constant of best model rate equation the experimental data obtained at temperatures $55^{\circ} \mathrm{C}, 50^{\circ} \mathrm{C}$ and $35^{\circ} \mathrm{C}$ should be fitted to this kinetic model. Activation energies and pre exponential factors can be calculated graphically by plotting the natural logarithm of the rate constant versus the inverse of reaction temperature in Kelvin. Each plot can be fitted to a straight line its slope equals (-E/R), where $\mathrm{E}$ is the activation energy and $\mathrm{R}$ is the universal gas constant, while the intercept with $\mathrm{y}$-axis is the natural logarithm of pre exponential factor.

\subsection{Characterization of Produced Biodiesel}

The produced biodiesel was characterized using standard ASTM methods for each property to be tested. Fractions of the produced methyl esters were characterized using Agilent HP 6890 GC system equipped with flame ionization detector FID. The column used was hp 5 column type.

Aniline point was characterized to give an estimation of the cetane number of produced biodiesel using the following relation:

$$
\text { D.I. }=\frac{\text { Aniline point }{ }^{\circ} \mathrm{F} * \text { A.P.I }}{100}
$$

where D.I. is the diesel index of produced biodiesel and A.P.I is a measure of its specific gravity;

$$
\text { A.P.I }=\frac{141.5}{\text { Sp.Gr. }}-131.5
$$

These two properties - aniline point and D.I. - are good indicators to cetane number of biodiesel. They are used due to the difficulty of 
measuring cetane number directly. Following is a simple relation that can be used to estimate cetane number C.N. using diesel index.

$$
\text { C.N. }=0.72 * \text { D.I. }+10
$$

\subsection{Product Stability}

In the part of studying biodiesel stability, acid value and viscosity of produced biodiesel are measured along three months as indicators of stability. When these values highly change this means that biodiesel is at low stability and it should be further processed and purified to increase its stability and to match ASTM standards.

Each week over storage period acid value and viscosity tests are done to study biodiesel stability; acid value test was carried out by titrating one gram of biodiesel in $25 \mathrm{~mL}$ ethanol by KOH $0.1 \mathrm{~N}$ using phenolphthalein as indicator, then we can calculate the acid value A.V. from the following relation,

$$
A . V .=\frac{\left(V-V_{b}\right) * N * E q . w t .}{W_{F A M E}}
$$

where $\mathrm{V}$ and $\mathrm{V}_{\mathrm{b}}$ are the volumes of $0.1 \mathrm{~N} \mathrm{KOH}$ needed for titration in $\mathrm{mL}$ for both the oil sample and blank sample, $\mathrm{N}$ is the normality of $\mathrm{KOH}$ which equals about 0.1 geqL $^{-1}$, Eq.wt is the equivalent weight of $\mathrm{KOH}=56.1$ and $\mathrm{W}_{\mathrm{FAME}}$ is the biodiesel sample mass in $\mathrm{g}$.

Viscosity was tested using a capillary tube viscometer. Measuring viscosity using this viscometer is done by measuring the flow time of the fluid. It should be noticed that the measured flow time should be $\geq 50$ seconds to have accurate results.

\section{Results and Discussion}

\subsection{Transesterification Optimum Conditions}

The effect of operating conditions on alkaline catalyzed transesterification of soybean and sunflower waste vegetable oil mixture was investigated taking into consideration to achieve maximum yield of biodiesel.

\subsubsection{Effect of Catalyst on WVO Transesterification}

The effect of $\mathrm{KOH}$ and $\mathrm{NaOH}$ loadings on the methyl ester conversion was studied in the range of 0.2 to $2 \mathrm{wt} \%$ (of initial oil weight), at $65 \pm 1{ }^{\circ} \mathrm{C}$, 60 min and 6:1 molar ratio. Results are shown in Fig. 1; it may be observed that the yield of the methyl esters was the highest at 1\% catalyst loading, and then decreased as the catalyst loading was increased.

On using catalyst loadings higher than $1 \mathrm{wt} \%$, the yield decreased and resulted in no clear separation during settling, while during washing with warm de-ionized water more soap was observed due to presence of excess catalyst which favors saponification process.

On the other hand using $\mathrm{KOH}$ gives higher yield than $\mathrm{NaOH}$ which favors soap formation. So $\mathrm{KOH}$ is preferred as alkaline catalyst.

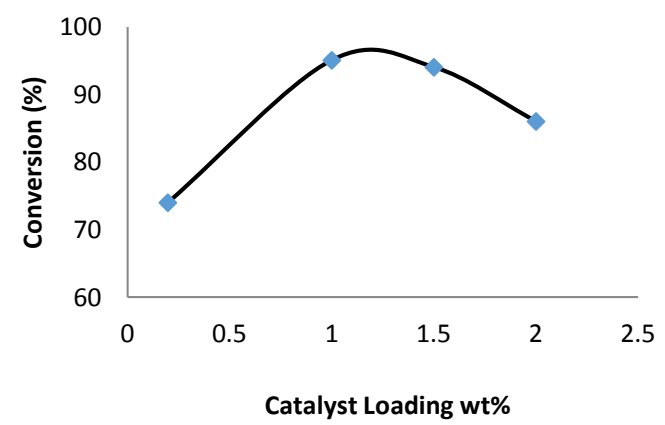

Fig. 1 Effect of catalyst loading on biodiesel production

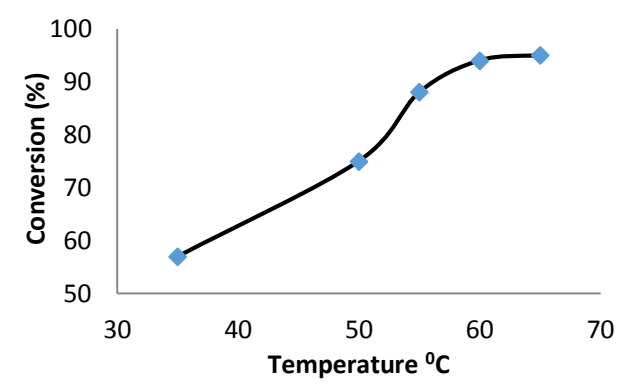

Fig. 2 Effect of reaction temperature on biodiesel production

https://doi.org/10.30799/jacs.195.18040305

Cite this Article as: E.G. Al-Sakkari, S.T. El-Sheltawy, A. Soliman, I. Ismail, Transesterification of low FFA waste vegetable oil using homogeneous base catalyst for biodiesel production: Optimization, kinetics and product stability, J. Adv. Chem. Sci. 4(3) (2018) 586-592.

\subsubsection{Effect of Reaction Temperature on WVO Transesterification}

Higher temperatures decrease the time required to reach maximum conversion [37]. Transesterification can be conducted at various temperatures ranging from room temperature to the boiling point of the alcohol employed $\left(65^{\circ} \mathrm{C}\right.$ in case of methanol) so that the reactor does not need to be pressurized [29]. Thus, the usual temperature used during transesterification in most literature ranges from $60^{\circ} \mathrm{C}$ to $65^{\circ} \mathrm{C}$. When the reaction temperature closes or exceeds the boiling point of methanol 65 ${ }^{\circ} \mathrm{C}$ ), the methanol will vaporize and form a large number of bubbles which may inhibit the reaction [38].

Many studies were done to determine the optimum reaction temperature, Refaat [39] reported an optimum temperature of $65{ }^{\circ} \mathrm{C}$, while Meng et al. [38] reported $50^{\circ} \mathrm{C}$ as the optimum temperature. After this study it was observed that the optimum temperature for the reaction is $65^{\circ} \mathrm{C}$ which can be illustrated in Fig. 2 .

\subsubsection{Effect of Reaction Time on WVO Transesterification}

Reaction time in this study was investigated using the optimal parameters obtained in the previous sections. Several investigators found that the transesterification reaction starts very fast and almost $80 \%$ of the conversion takes place in the first $30 \mathrm{~min}$ and after $1 \mathrm{~h}$, almost $93-98 \%$ conversion of the triglycerides into ester takes place $[40,41]$. In the present work, the effect of reaction time from $7.5 \mathrm{~min}$ to $3 \mathrm{~h}$ on the reaction yield was studied. Fig. 3 shows the conversion profile along reaction time. It is clear that the conversion was lower for shorter times and increased as the time was increased to $1 \mathrm{~h}$, increasing the reaction time to beyond one hour no noticeable change in the yield was detected, the ester yield changed slightly.

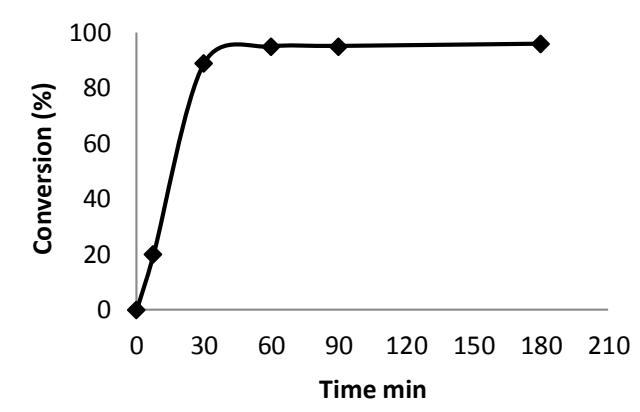

Fig. 3 Effect of reaction time on biodiesel production

\subsubsection{Effect of Alcohol Type on WVO Transesterification}

As mentioned before different types of alcohols were used to find out the optimum type for transesterification. All reactions were held at temperature of $65^{\circ} \mathrm{C}$. Table 2 summarizes the comments on using each type.

Table 2 Effect of different alcohols used on biodiesel production

\begin{tabular}{ll}
\hline Alcohol & Comments \\
\hline Propanol and iso- & Very difficult separation (ester forms homogeneous \\
butanol & mixture with glycerol) \\
Ethanol & Low rate of reaction and difficult separation of glycerol \\
Methanol & from ester
\end{tabular}

Higher molecular weight alcohols act as co-solvents for both produced alkyl ester and glycerol. Due to this fact, separation of different phases becomes difficult on using heavier alcohols than methanol. From the previous table it may be observed that methanol is the best alcohol can be used for biodiesel production.

\subsubsection{Effect of Agitation Speed on WVO Transesterification}

Since this reaction can only occur in the interfacial region between the liquids and also due to the fact that fats and alcohols are not totally miscible, transesterification is a relatively slow process. As a result, agitation is required to increase the area of contact between the two immiscible phases [42].

The agitation intensity appears to be of a particular importance for the alcoholysis process. The mass transfer of triglycerides from the oil phase towards the methanol-oil interface could be a critical step limiting the rate of alcoholysis reaction because the reaction mixture is heterogeneous, consisting of two immiscible phases. Poor mass transfer between two phases in the initial phase of the reaction results in a slow reaction rate, 
and consequently the reaction will be controlled by mass transfer [43]. Therefore, decrease in agitation intensity is expected to alter the kinetics of the transesterification reaction [39].

Using the optimum conditions from the previous sections, optimum agitation speed was investigated by carrying out the reaction at different speeds from zero rpm to $800 \mathrm{rpm}$. It was observed that at no or relatively low agitation speeds there was no noticeable conversion. On the other hand, higher agitation speed (above $500 \mathrm{rpm}$ ) lowers biodiesel production due to soap formation which increases with increasing agitation speed. The optimum agitation speed was found to be within the range of $400 \mathrm{rpm}$ to $500 \mathrm{rpm}$.

\subsection{Kinetic Modeling}

Many researchers studied transesterification reactions kinetics intensively [44-46]. The main concern of these studies is to obtain a reasonable reaction rate expression in order to have a proper design for a reactor its aim is the production of biodiesel. When the transesterification reaction is catalyzed by a homogeneous catalyst like $\mathrm{KOH}$, the reaction rate can take the power law form such as first and second order [47]. It should be noticed that, development of reaction rate equation is done based on reaction mechanism as well as the controlling step of this reaction [48].

Some studies suggested that the transesterification of soybean oil using homogeneous catalyst can follow a second order rate equation [43, 49-51]. While, Darnoko and Cheryan [52] observed that the reaction followed second order rate model in the early stages of reaction and then in latter stages it obeyed first order model adequately. All these works were based on the assumption of kinetically controlled reaction and that there are no side reactions [53]. In their research studies, Noureddini and Zhu, [43], Bambase et al. [49], and Darnoko and Cheryan [66] selected the step of triglyceride conversion to diglyceride as controlling step while Karmee et al. [50] suggested the conversion of diglyceride to monoglyceride as determining step and Vicente et al. [51] selected conversion of monoglycerides to glycerol reaction as being the controlling step. Recently, as mentioned before in section 2.3., transesterification kinetics are being studied on the basis of the overall reaction for time saving and simplification of calculations [34-35], this is what had been done through the present study and this method gave good results as will be shown.

Reactions took place at constant agitation speed of $400 \mathrm{rpm}$, molar ratio of $6: 1$ and catalyst loading of $1 \%$ of the original weight of WVO at four different temperatures $65,55,50$ and $35{ }^{\circ} \mathrm{C}$. Conversions at different temperatures are plotted against time in Fig. 4.

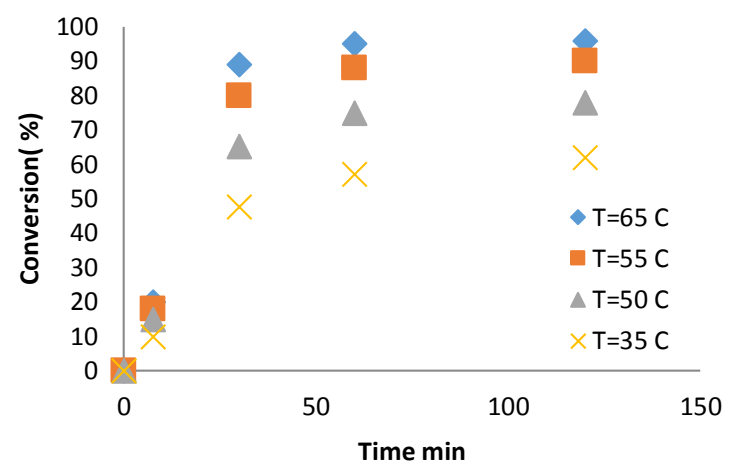

Fig. 4 WVO Conversion along Reaction Time at Different Temperatures

As mentioned before, six power law models were suggested to describe the base catalyzed transesterification of WVO.

\subsubsection{Irreversible Kinetic Models}

After plotting the data obtained at $65^{\circ} \mathrm{C}$ according to different cases e.g. first order and second order cases-, Eqs.(11) and (12) were obtained.

$r=0.0334 *[T G]$

$r=0.275 *[T G]^{2}$

Graphs of concentrations of both oil and biodiesel against reaction time for these two models are illustrated in Figs. 5 and 6.

Determination coefficient $\mathrm{R}^{2}$ for both first and second order irreversible models are about 0.8 and 0.94 respectively. It may be observed that at the first reaction stages the first order model offers good fitting while at later stages data can be fitted to second order irreversible model. In the case of irreversible model with variable methanol concentration the formula of rate equation take the form presented in Eq.(13).

https://doi.org/10.30799/jacs.195.18040305 $r=0.00019 *[T G] *[M A]^{3}$

Graph of concentrations of both oil and biodiesel against reaction time for this model is illustrated in Fig. 7.

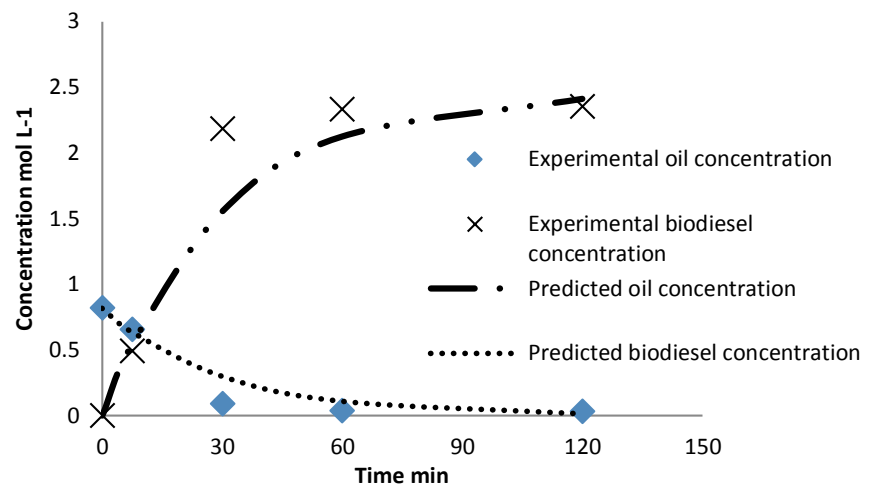

Fig. 5 First order irreversible model

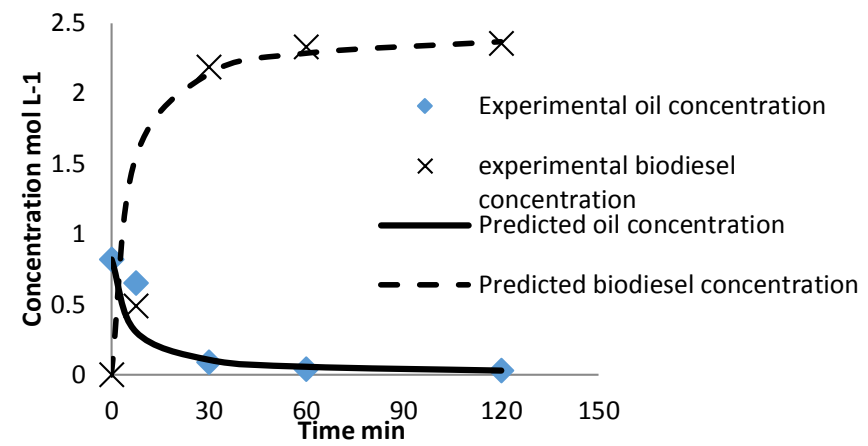

Fig. 6 Second Order Irreversible Model

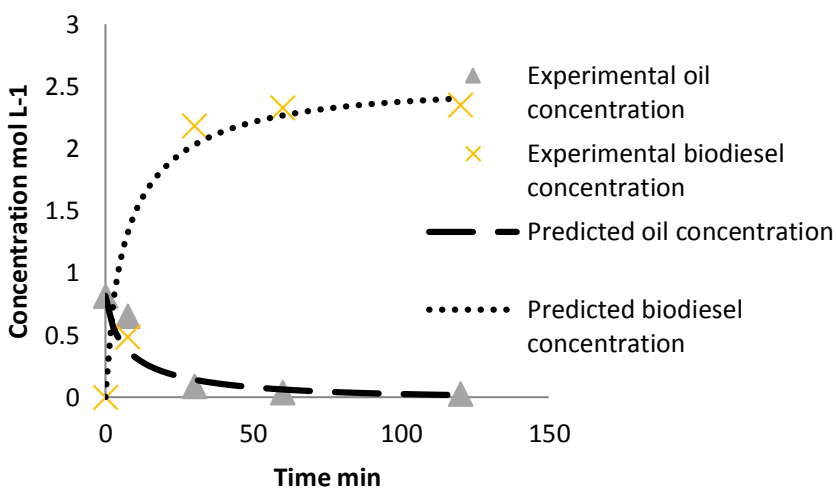

Fig. 7 Variable Methanol Concentration Irreversible Model

Determination coefficient $\mathrm{R}^{2}$ for model is about 0.8. As shown in Fig. 7 , this model may introduce a good fit but still the first order model introduce the best fit in the first reaction stages while the second order model is the best one to describe the later stages.

\subsubsection{Reversible Kinetic Models}

Eqs. $(14,15)$ represent the obtained reversible first and second order kinetic models while Figs. 5 and 6 display the results of these models.

$$
\begin{aligned}
& r_{s}=0.324 *[T G]-0.2565 *[G L] *[F A M E]^{3} \\
& r_{s}=0.5974 *[T G]^{2}-0.132 *[G L] *[F A M E]^{3}
\end{aligned}
$$

Determination coefficients of these models are 0.95 and 0.6 . This result indicates the poor fitting of second order reversible model which is also obvious from Fig. 9. First order reversible model may introduce a good fit for the experimental data. However, on comparing the results in Fig. 8 with those in Figs. 5 and 6, it can be observed that first order model still can represent the kinetics of early reaction stages while the second order irreversible model can describe the later stages of the reaction adequately. Based on these observations, more tests should be performed to select the best kinetic model.

The last generated model in this part is the one that takes into consideration the change of methanol concentration along reaction time. The mathematical statement that represents this model is shown in Eq.(16). 
$r=0.000485 *[T G] *[M A]^{3}-0.000397 *[G L] *[F A M E]^{3}$

Unfortunately, this model introduces an inadequate and poor fitting as illustrated in Fig. 10, so it cannot be used to describe the reaction kinetics.

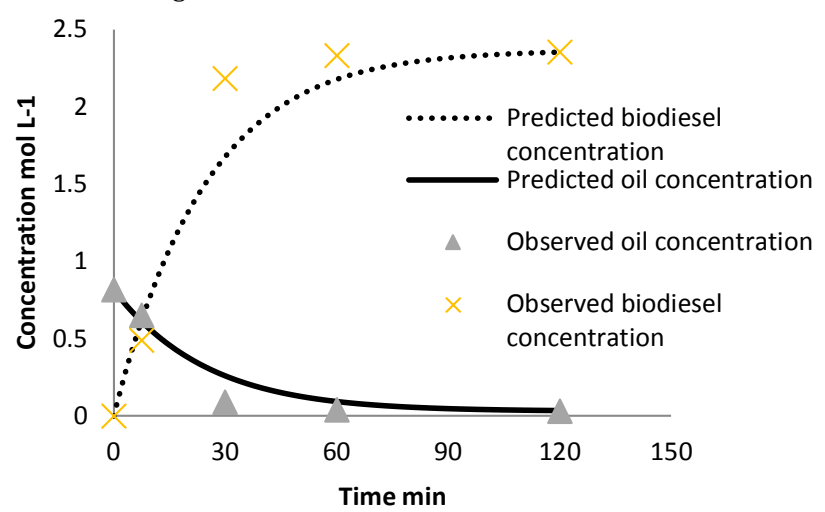

Fig. 8 First order reversible model

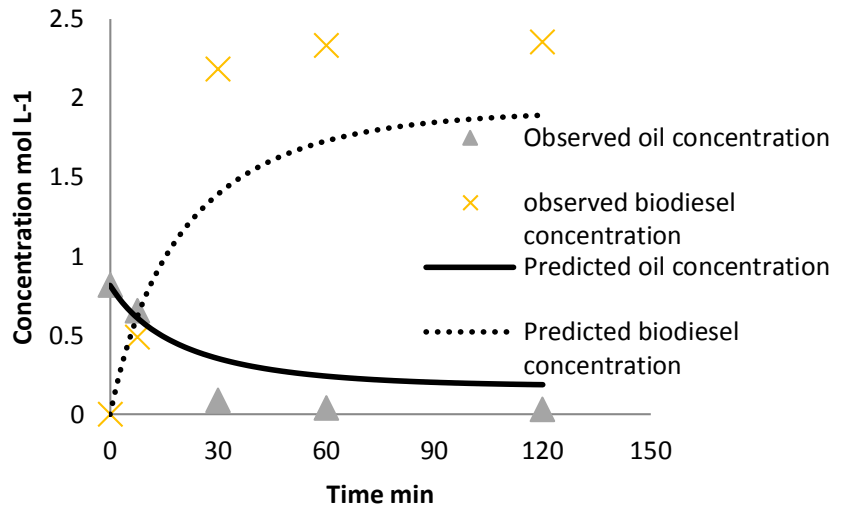

Fig. 9 Second order reversible model

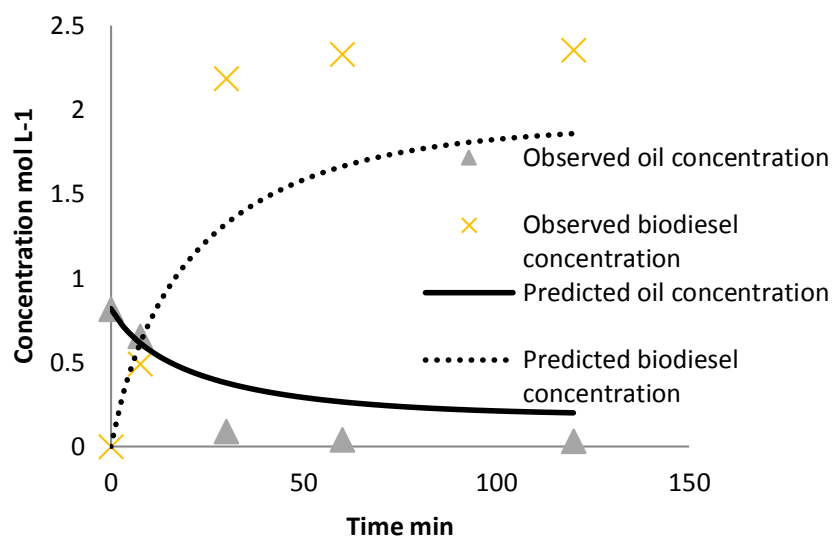

Fig. 10 Variable methanol concentration reversible model

\subsubsection{Selection of Best Available Model}

As observed there is more than one model can fit the experimental data as well as having high determination coefficients, so additional methods should be employed to select the best model to describe the kinetics of WVO transesterification. One of the most used methods used is the minimization of squared errors summation. It may be noticed from the previous figures that there are models that can fit the observed data at the early stages of WVO transesterification while others can describe the later stages, so the comparison between squared errors summation will be divided into two section one for the first stages while the other one is for the late stages. Tables 3 and 4 summarize the results of these comparisons. It should be noted that the error is equal to the difference between the predicted or calculated value of biodiesel concentration and the observed or experimental one.

From Tables 3 and 4, it may be concluded that the best model to describe the early stages of WVO homogeneous base catalyzed transesterification is the first order irreversible model. On the other hand, irreversible second order model is the best model to fit observed data at the reaction late stages.

https://doi.org/10.30799/jacs.195.18040305
Table 3 Summation of squared errors for some suggested kinetic models to describe the first reaction stages

\begin{tabular}{ll}
\hline Suggested MODEL & Summation of Squared Error \\
\hline Irreversible First Order Model & 0.0003 \\
Irreversible Second Order Model & 0.1119 \\
Irreversible Model (Variable Methanol & 0.0809 \\
Concentration) & \\
Reversible First Order Model & 0.0016 \\
\hline
\end{tabular}

Table 4 Summation of squared errors for some suggested kinetic models to describe the late reaction stages

\begin{tabular}{ll}
\hline Suggested Model & Summation of Squared Error \\
\hline Irreversible First Order Model & 0.0494 \\
Irreversible Second Order Model & 0.0005 \\
Irreversible Model (Variable Methanol & 0.0032 \\
Concentration) & \\
Reversible First Order Model & 0.0283 \\
\hline
\end{tabular}

Reversible First Order Model

\subsubsection{Activation Energies and Pre Exponential Factors}

Different values of rate constants at different temperatures are illustrated in Table 5.

Table 5 Rate constants at different temperatures

\begin{tabular}{lllll}
\hline \multirow{2}{*}{ Constant } & \multicolumn{4}{l}{ Temperature ${ }^{\circ} \mathrm{C}$} \\
\cline { 2 - 5 } & 65 & 55 & 50 & 35 \\
\hline $\mathrm{K}_{1}$ (first order) $\mathrm{min}^{-1}$ & 0.0334 & 0.0239 & 0.0157 & 0.0099 \\
$\mathrm{~K}_{2}$ (second order) $\mathrm{mol}^{-1} \mathrm{~L} \mathrm{~min}{ }^{-1}$ & 0.2750 & 0.1059 & 0.0428 & 0.0196 \\
\hline
\end{tabular}

Figs. 11 and 12 illustrate the plots of the natural logarithm of each rate constant versus the inverse of reaction temperature in Kelvin. Table 6 summarizes the findings obtained from this part.

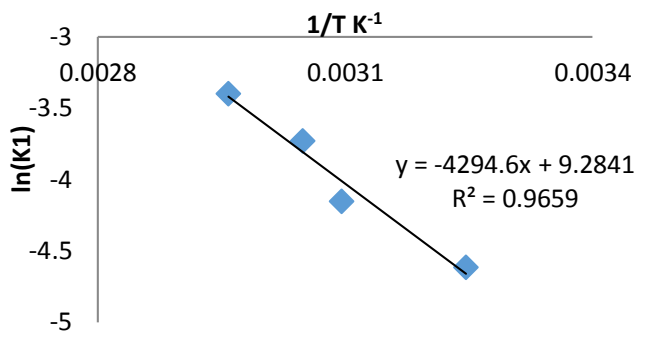

Fig. $11 \mathrm{Ln} \mathrm{K}_{1}$ versus $1 / \mathrm{T} \mathrm{K}^{-1}$

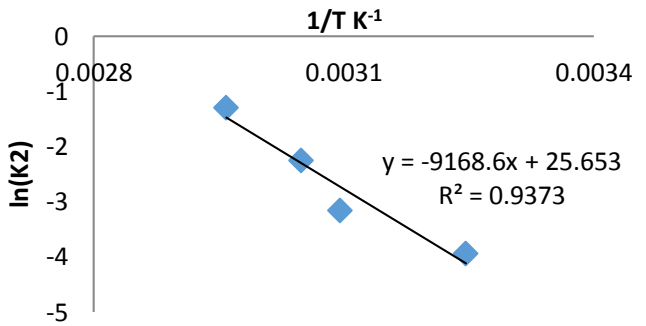

Fig. 12 Ln $\mathrm{K}_{2}$ versus $1 / \mathrm{T} \mathrm{K}^{-1}$

Table 6 Activation energies and pre-exponential factors

\begin{tabular}{lll}
\hline Constant & Activation Energy kJ mol-1 & Pre-exponential factor \\
\hline $\mathrm{K}_{1} \mathrm{~min}^{-1}$ & 35.7053 & $1.1 * 10^{4} \mathrm{~min}^{-1}$ \\
$\mathrm{~K}_{2} \mathrm{~mol}^{-1} \mathrm{~L} \mathrm{~min}^{-1}$ & 76.2277 & $1.38 * 10^{11} \mathrm{~mol}^{-1} \mathrm{~L} \mathrm{~min}^{-1}$ \\
\hline
\end{tabular}

\subsection{Characterization of Produced Biodiesel}

The properties of produced biodiesel are shown in Table 7. Chemical composition of the produced biodiesel is illustrated in Table 8 .

Table 7 Properties of produced biodiesel

\begin{tabular}{ll}
\hline Property & Value \\
\hline Viscosity $\mathrm{mm}^{2} / \mathrm{s} @ 40^{\circ} \mathrm{C}$ & 4.5 \\
Density $\mathrm{g} / \mathrm{cm}^{3}$ & 0.875 \\
Aniline Point ${ }^{\circ} \mathrm{C}$ & 84.5 \\
Flash Point ${ }^{\circ} \mathrm{C}$ & 140 \\
Cloud Point $^{\circ} \mathrm{C}$ & 3 \\
Pour Point ${ }^{\circ} \mathrm{C}$ & -2 \\
Acid Value $\mathrm{mg} \mathrm{KOH} / \mathrm{g}$ & 0.8 \\
Calorific Value $\mathrm{kJ} / \mathrm{kg}$ & 39000 \\
Diesel Index & 55.56 \\
Cetane Number & 50 \\
\hline
\end{tabular}


Table 8 Chemical composition of produced biodiesel

\begin{tabular}{llllll}
\hline Fatty Acid & Palmitic & Stearic & Oleic & Linoleic & Linolenic \\
\hline Carbon Number & $16: 0$ & $18: 0$ & $18: 1$ & $18: 2$ & $18: 3$ \\
Percentage\% & 15 & 8 & 26.1 & 43.25 & 7.65 \\
\hline
\end{tabular}

\subsection{Produced Biodiesel Stability}

The duration of this study was limited to three months. During these three months acid value and viscosity of the stored samples were determined as indicators for biodiesel stability.

\subsubsection{Acid value}

Degradation of biodiesel quality is reflected by change in acid value mg $\mathrm{KOH} / \mathrm{g}$ of biodiesel. The changes of acid value during storage period are presented in Fig. 13.

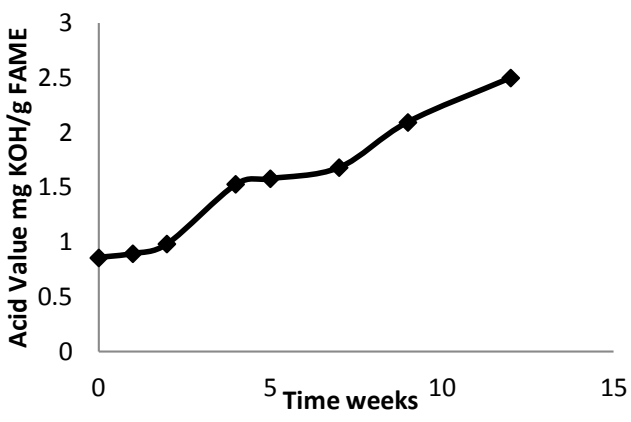

Fig. 13 Acid value change during storage

From this figure we can see that the rate of degradation during the first two weeks is small as the ambient temperature was around $18^{\circ} \mathrm{C}$ and did not change noticeably, also in the period between $4^{\text {th }}$ and $7^{\text {th }}$ week. However, in the period between $2^{\text {nd }}$ and $4^{\text {th }}$ week degradation was more rapid as the change in ambient temperature was relatively high, it reaches about $32^{\circ} \mathrm{C}$, and the same problem happened in the period between $7^{\text {th }}$ and $9^{\text {th }}$ week as the ambient temperature reaches $40{ }^{\circ} \mathrm{C}$, storage period was from February to May.

Other researchers studied biodiesel stability and its blends with petro diesel. Chakraborty and Baruah [54] tested biodiesel acid value during storage and they found out that identical rate of increase in acid value is observed in case of three samples viz., B100, B30 and B2 0 up to $8^{\text {th }}$ week of storage. Rate of increase in acid value of neat biodiesel (B100) accelerates after $8^{\text {th }}$ week of storage. The rates of increase in acid value of B5 and B10 during storage are lesser than the remaining three samples. During storage, the esters are first oxidized to form peroxides, which then undergo complex reaction including a split into more reactive aldehydes which further oxidize into acids, and thus increase in the acid value [55]. However, hydrolysis of ester into alcohol and acids by the traces of water present in samples is also thought to increase acid value [55]. The higher acid value exhibited by the blends (B20 and B30) could be attributed to differences in magnitude of hydrolysis reaction due to the presence of higher concentration of biodiesel in diesel [56].

\subsubsection{Viscosity}

Viscosity of sample was determined over the storage period, the changes of viscosity samples during storage period are presented in Fig. 14.

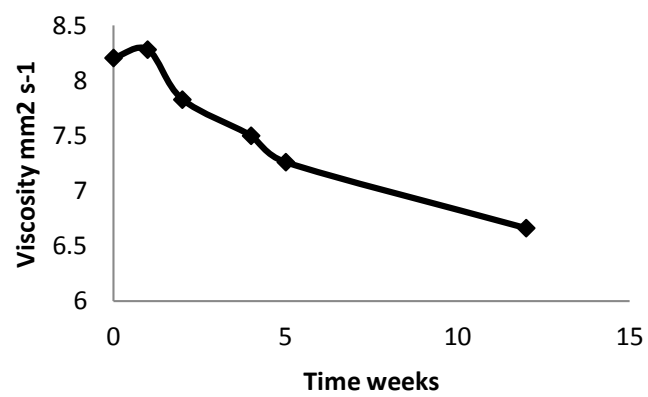

Fig. 14 Viscosity change during storage

As shown in the figure the viscosity increased during the first week and this could be due to evaporation of residual methanol that was not removed during drying. However, during the next weeks viscosity decreased and that may happened as a result of residual oil oxidation with https://doi.org/10.30799/jacs.195.18040305 different mechanisms which produced shorter chain compounds such as shorter fatty acids, resulting in acid value increase during storage, as well as aldehydes and ketones. Similar observations, i.e. increase of the acid value and decrease of viscosity of the stored samples, were detected by Polczmann et al. [57]. It should be noted that oxidation is enhanced by light exposure, presence of metals and temperature increase.

Chakraborty and Baruah [54] studied the viscosity of biodiesel and its blends with petro diesel and they found that in general, viscosity values of all the samples increased with time of storage and this might be attributed to the oxidation process. Further, it is also noticed that except the $12^{\text {th }}$ week old B100 sample, viscosity values of all other samples remain within the limit of ASTM D $67516 \mathrm{~mm}^{2} \mathrm{~s}^{-1}$ ). The rates of increase in viscosity during storage up to 12 weeks are found to vary amongst the samples. Neat biodiesel (B100), with an increase from $5.17 \mathrm{~mm}^{2} \mathrm{~s}^{-1}$ to $6.2 \mathrm{~mm}^{2} \mathrm{~s}^{-1}$ during the 12 weeks, exhibits lesser rate of increase compared to blended samples. Evidence of formation of insoluble products due to interaction of biodiesel and petro diesel is reported elsewhere. Possible chemical reaction and formation of products during interaction of biodiesel and petro diesel might be the reason of varying rates of increase in viscosity amongst the samples in their study.

\subsection{Recommendations from the Experimental Phase to be Applied in the}

It is recommended that oil residues should be eliminated. Washing of biodiesel should be done to remove any contaminations, then elimination of any suspended water droplets after washing to avoid hydrolysis. Storage tank of biodiesel should be insulated with good insulation to avoid the effect of ambient conditions on the stored biodiesel. To increase biodiesel oxidation stability, some additives should be added to the stored quantity of biodiesel like (six phenolic antioxidants viz. Vitamin E $(\alpha-$ tocopherol), butylated hydroxyanisole (BHA), pyrogallol (PY), propyl gallate (PG), dibutylated hydroxytoluene (BHT) and tert-butyl hydroxyquinone (TBHQ) with percentage of $1 \mathrm{wt} \%$ of biodiesel $[54,58]$.

\section{Conclusion}

From the above investigations it may be concluded that the optimum conditions for biodiesel production from WVO through base catalyzed transesterification, using methanol as an alcohol and $\mathrm{KOH}$ as alkaline catalyst, are (60 $\mathrm{min}, 1 \mathrm{wt} \%$ catalyst loading, $65^{\circ} \mathrm{C}$ and $\left.400 \mathrm{rpm}\right)$. The kinetics of this reaction can be described by irreversible first order model in the early stages while later stages can be adequately fitted to irreversible second order model. To avoid the change of acid value and viscosity of produced biodiesel and to enhance its stability along storage period, some actions should be taken such as removal of oil contaminations, good insulation of storage tanks and the addition of some additives like (TBHQ) to decrease biodiesel oxidation and degradation.

\section{References}

[1] S.K. Hoekman, Biofuels in the US - challenges and opportunities, Renew. Energy 34 (2009) 14-22.

[2] C.W. Lin, S.W. Tsai, Production of biodiesel from chicken wastes by various alcohol-catalyst combinations, Jour. Energy South. Afr. 26 (2015) 36-45

[3] M.R. Nanda, Z. Yuan, W. Qin, M.A. Poirier, X. Chunbao, Purification of crude glycerol using acidification: effects of acid types and product characterization, Austin Chem. Eng. 1 (2014) 1004-1-7.

[4] G. Kafuku, K.T. Lee, M. Mbarawa, Non-catalytic and catalytic transesterification: a reaction kinetics comparison study, Int. Jour. Green Energy 12 (2015) 551558.

[5] N. Saifuddin, H. Refal, P. Kumaran, Rapid Purification of glycerol by-product from biodiesel production through combined process of microwave assisted acidification and adsorption via chitosan immobilized with yeast, Res. Jour. Appl. Sci. Eng. Tech. 7 (2014) 593-602.

[6] S. Pathak, Acid catalyzed transesterification, Jour. Chem. Pharm. Res. 7 (2015) 1780-1786

[7] A.P. Singh Chouhan, A.K. Sarma, Modern heterogeneous catalysts for biodiesel production: A comprehensive review, Renew. Sustain. Energy Rev. 15 (2011) 4378-4399.

[8] F. Cao, Y. Chen, F. Zhai, J. Li, J. Wang, X. Wang, S. Wang, W. Zhu, Biodiesel production from high acid value waste frying oil catalyzed by superacid heteropolyacid, Biotech. Bioeng. 101 (2008) 93-100.

[9] L. Bournay, D. Casanave, B. Delfort, G. Hillion, J.A. Chodorge, New heterogeneous process for biodiesel production: A way to improve the quality and the value of the crude glycerin produced by biodiesel plants, Catal. Today $106(2005)$ 190-192.

[10] T.T.B. Lan, P.N. Hoa, Lipase catalysis for transesterification produces biodiesel using coconut oil as main raw material source, Biol. Chem. Res. 2015 (2015) 258-267. Phase of Process Design 
[11] A.E. Ghaly, D. Dave, M.S. Brooks, S. Budge, Production of biodiesel by enzymatic transesterification: Review, Am. J. Biochem. Biotech. 6 (2010) 54-76.

[12] L.F. Chuah, J.J. Klemes, S. Yusup, A. Bokhari, M.M. Akbar, Z.K. Chong, Kinetic studies on waste cooking oil into biodiesel via hydrodynamic cavitation, J. Clean. Prod. 146 (2016) 47-56.

[13] A. Bokhari, L.F. Chuah, S. Yusup, J.J. Klemes, M.M. Akbar, R.N.M. Kamil, Cleaner production of rubber seed oil methyl ester using a hydrodynamic cavitation: optimization and parametric study, Jour. Clean. Prod. 136 (2016) 31-41.

[14] L.C. Meher, D.V. Sagar, S.N. Naik, Technical aspects of biodiesel production by transesterification-a review, Renew. Sustain. Energy Rev. 10 (2006) 248-268.

[15] D. Kusdiana, S. Saka, Kinetics of transesterification in rapeseed oil to biodiesel fuel as treated in supercritical methanol, Fuel 80 (2001) 693-698.

[16] M. Shah, M. Tariq, S. Ali, Q.X. Guo, Y. Fu, Transesterification of jojoba oil, sunflower oil, neem oil, rocket seed oil and linseed oil by tin catalysts, Biomass. Bioener. 70 (2014) 225-229.

[17] K.G. Georgogianni, M.G. Kontominas, E. Tegou, D. Avloitis, V. Gergis, Biodiesel production: reaction and process parameters of alkali-catalyzed transesterification of waste frying oils, Energy Fuels 21 (2007) 3023-3027.

[18] A. Murugesan, C. Umarani, Production and analysis of biodiesel from nonedible oils-a review, Renew. Sustain. Energy Rev. 13 (2009) 825-834.

[19] J.M. Cerveró, J. Coca, S. Luque, Production of biodiesel from vegetable oils Grasas Y Aceites, Int. J. Fata Oils 59 (2008) 76-83.

[20] S.R. Medipally, F.M. Yusoff, S. Banerjee, M. Shariff, Microalgae as sustainable renewable energy feedstock for biofuel production, BioMed. Res. Inter. 2015 (2015) 519513

[21] L.T. Thanh, K. Okitsu, L.V. Boi, Y. Maeda, Catalytic technologies for biodiesel fuel production and utilization of glycerol: A Review, Catalysts 2 (2012) 191-222.

[22] M. Agarwal, G. Chauhan, S.P. Chaurasia, K. Singh, Study of catalytic behavior of $\mathrm{KOH}$ as homogeneous and heterogeneous catalyst for biodiesel production, Jour. Taiwan Inst. Chem. Eng. 43 (2012) 89-94.

[23] M. Hájek, F. Skopal, Purification of the glycerol phase after transesterification of vegetable oils, 44th International Petroleum Conference, Bratislava, Slovak Republic, 2009.

[24] R.W.N.W. Isahak, Z.A.C. Ramli, M. Ismail, J.M. Jahim, M.A. Yarmo, Recovery and purification of crude glycerol from vegetable oil transesterification, Sep. Purif. Rev. 44 (2015) 250-267.

[25] Y. Zhang, M.A. Dube, D.D. McLean, M. Kates, Biodiesel production from waste cooking oil, Process design and technological assessment, Bioresour. Technol. 89 (2003) 1-16.

[26] C. Kiwjaroun, C. Tubtimdee, P. Piumsomboon, LCA studies comparing biodiesel synthesized by conventional and supercritical methanol methods, Jour. Clean. Prod. 17 (2009) 143-153.

[27] A.C. Pinto, L.N. Guarieiro, M.J. Rezende, N.M. Ribeiro, E.A. Torres, Biodiesel: An overview, J. Brazil Chem. Soc. 16 (2005) 1313-1330.

[28] J. Van Gerpen, Biodiesel processing and production, Fuel Proc. Technol. 86 (2005) 1097-1107.

[29] A. Singh, B. He, J. Thompson, J. Van Gerpen, Process optimization of biodiesel production using different alkaline catalysts, Appl. Eng. Agr. 22 (2006) 597600.

[30] H.V. Lee, R. Yunus, Process optimization design of jatropha-based biodiesel production using response surface methodology, Fuel Proc. Technol. 92 (2011) 2420-2428.

[31] D.Y.C. Leung, Y. Guo, Transesterification of neat and used frying oil: Optimization for biodiesel production, Fuel Proc. Technol. 87 (2006) 883-890.

[32] N. Asikin-Mijana, H.V. Lee, Y.H. Taufiq-Yap, Synthesis and catalytic activity of hydration-dehydration treated clamshell derived $\mathrm{CaO}$ for biodiesel production, Chem. Eng. Res. Design 102 (2015) 368-377.

[33] Z.A. Shajaratun Nur, Y.H. Taufiq-Yap, M.F. Rabiah Nizah, S.H. Teo, O.N. Syazwani, A. Islam, Production of biodiesel from palm oil using modified Malaysian natural dolomites, Energy Conver. Manag. 78 (2014) 738-744.

[34] G. Moradi, M. Mohadesi, S. Hosseini, Y. Davoodbeygi, R. Moradi, DM Water Plant sedimentation as a cheap and waste source of catalyst for biodiesel production, Int. J. Chem. Reactor Eng. 14 (2015) 113-124.
[35] D.J. Vujicic, D. Comic, A. Zarubica, R. Micic, G. Boskovi, Kinetics of biodiesel synthesis from sunflower oil over CaO heterogeneous catalyst, Fuel 89 (2010) 2054-2061.

[36] M. Shacham, M.B. Cutlip, M. Elly, Polymath Version 6.0, CACHE Corporation, USA, 2004.

[37] D. Pimentel, Biofuels, solar and wind as renewable energy system, Springer, USA, 2008

[38] X. Meng, G. Chen, Y. Wang, Biodiesel production from waste cooking oil via alkali catalyst and its engine test, Fuel Proc. Technol. 89 (2008) 851-857.

[39] A.A. Refaat, Different techniques for the production of biodiesel from waste vegetable oil, Int. J. Environ. Sci. Tech. 7 (2010) 183-213.

[40] A. Srivastava, R. Prasad, Triglycerides-based diesel fuels, Renew. Sustain Energy Rev. 4 (2000) 11-33.

[41] F. Ma, M.A. Hanna, Biodiesel production: a review, Bioresour. Technol. 70 (1999) 1-15.

[42] A.K. Singh, S. Fernando, Catalyzed fast transesterification of soybean oil using ultrasonication, American Society of Agricultural Engineers, ASAE Annual Meeting, Paper \# 066220, 2006.

[43] H. Noureddini, D. Zhu, Kinetics of transesterification of soybean oil, Jour. Am. Oil Chem. Soc. 74 (1997) 1457-1463.

[44] K. Muazu, I.A. Mohammed-Dabo, S.M. Waziri, A.S. Ahmed, I.M. Bugaje, U.A.S Zanna, Kinetic modeling of transesterification of Jatropha curcas seed oil using heterogeneous catalyst, Eng. Technol. 2 (2015) 87-94.

[45] E. Aransiola, M. Daramola, T. Ojumu, B. Solomon, S. Layokun, Homogeneously catalyzed transesterification of Nigerian Jatropha curcas oil into biodiesel: A kinetic study, Mod. Res. Catal. 2 (2013) 83-89.

[46] A. Birla, B. Singh, S.N. Upadhyay, Y.C. Sharma, Kinetics studies of synthesis of biodiesel from waste frying oil using a heterogeneous catalyst derived from snail shell, Bioresour. Technol. 106 (2012) 95-100.

[47] D. Krishnan, A kinetic study of biodiesel in waste cooking oil, Afr. Jour Biotechnol. 11 (2012) 9797-9804.

[48] F. Allain, J.F. Portha, E. Girot, L. Falk, A. Dandeu, V. Coupard, Estimation of kinetic parameters and diffusion coefficients for the transesterification of triolein with methanol on a solid $\mathrm{ZnAl}_{2} \mathrm{O}_{4}$ catalyst, Chem. Eng. Jour. 283 (2016) 833-845.

[49] M.E. Bambase, N. Nakamura, J. Tanaka, M. Matsumura, Kinetics of hydroxidecatalyzed methanolysis of crude sunflower oil for the production of fuel-grade methyl esters, Jour. Chem.Technol. Biotechnol. 82 (2007) 273-280.

[50] S.K. Karmee, D. Chandna, R. Ravi, A. Chadha, Kinetics of base-catalyzed transesterification of triglycerides from Pongamia oil, Jour. Am. Oil Chem. Soc. 83 (2006) 873-877.

[51] G. Vicente, M. Martínez, J. Aracil, A. Esteban, Kinetics of sunflower oil methanolysis, Indust. Eng. Chem. Res. 44 (2005) 5447-5454.

[52] D. Darnoko, M. Cheryan, Kinetics of palm oil transesterification in a batch reactor, Jour. Am. Oil Chem. Soc. 77 (2000) 1263-1267.

[53] V.C. Eze, The use of meso-scale oscillatory baffled reactors for rapid screening of heterogeneously catalyzed biodiesel production reactions, Ph.D. Thesis, School of Chemical Engineering and Advanced Materials, Newcastle University, United Kingdom, 2014.

[54] M. Chakraborty, D.C. Baruah, Investigation of oxidation stability of Terminalia belerica biodiesel and its blends with petro-diesel, Fuel Proc. Technol. 98 (2012) 51-58.

[55] S. Schober, M. Mittelbach, The impact of antioxidants on biodiesel oxidation stability, Eur. Jour. Lipid Sci. Technol. 106 (2004) 382-389.

[56] P. Shah, C. Wee, J.M. White, S. Sanford, G. Meier, Experimental determination and thermodynamic modeling of water content in biodiesel-diesel blends, Renewable Energy Group, Inc, 2010.

[57] G. Polczmann, O. Toth, A. Beck, J. Hancsok, Investigation of storage stability of diesel fuels containing biodiesel produced from waste cooking oil, Jour. Clean. Prod. A 111 (2015) 85-92.

[58] G. Dwivedi, P. Verma, M.P. Sharma, Optimization of storage stability for karanja biodiesel using box-behnken design, Waste Biomass Valoriz. 9 (2015) 645655. 